\title{
CENP-A: the key player behind centromere identity, propagation, and kinetochore assembly
}

\author{
Valérie De Rop • Abbas Padeganeh • \\ Paul S. Maddox
}

Received: 9 August 2012 /Revised: 1 October 2012 / Accepted: 1 October 2012 /Published online: 26 October 2012

(C) The Author(s) 2012. This article is published with open access at Springerlink.com

\begin{abstract}
Chromosome segregation is the one of the great problems in biology with complexities spanning from biophysics and polymer dynamics to epigenetics. Here, we summarize the current knowledge and highlight gaps in understanding of the mechanisms controlling epigenetic regulation of chromosome segregation.
\end{abstract}

\section{Introduction}

Centromeres were first described by Walther Flemming as the primary constriction on condensed chromosomes, where cellular fibers, now known to be microtubules, attached during mitosis (Flemming 1882). Electron microscopy images later led to the realization that centromeres are chromosomal loci where the megadalton protein complex named the kinetochore assembles (Robbins and Gonatas 1964; Brinkley and Stubblefield 1966). The definition of centromeres, while still following these early rules, has become more complex with the discovery of molecular players involved in centromere identity. Counter intuitively, extensive studies on the expression and localization of different centromere components throughout the cell cycle have not led to a consensus mechanism that defines centromere specification. In this review, we focus on the latest discoveries in the field and specifically on epigenetic markers for centromere identity.

\section{Communicated by Erich Nigg}

V. De Rop $(\bowtie) \cdot$ A. Padeganeh $\cdot$ P. S. Maddox

Institute for Research in Immunology and Cancer (IRIC),

Department of Pathology and Cell Biology,

Université de Montréal,

C.P. 6128 , succursale Centre-ville,

Montréal, Québec H3C 3J7, Canada

e-mail: valerie.de.rop@umontreal.ca

P. S. Maddox

e-mail: paul.maddox@umontreal.ca

\section{CENP-A as an epigenetic marker for centromere identity}

Centromeres are epigenetically defined by a variant of histone $\mathrm{H} 3$, centromere protein-A (CENP-A). CENP-A was serendipitously discovered in 1985 by William Earnshaw in the course of immunoblotting and immunostaining experiments. Blotting serum isolated from CREST syndrome patients identified three recurrent bands common among many patients. Immunostaining using the same sera in tissue culture cells showed an enrichment at centromeres (Earnshaw and Rothfield 1985; Earnshaw et al. 1986; Valdivia and Brinkley 1985). These proteins were accordingly named centromere proteins A, B, and C. Later, biochemical approaches demonstrated that CENP-A copurified with histones and is a bona fide component of nucleosome particles (Palmer et al. 1987; Palmer et al. 1991). CENP-A contains a histone fold domain and is able to replace histone $\mathrm{H} 3$ in centromeric nucleosomes (Sullivan et al. 1994; Yoda et al. 2000). Sequence analysis of CENP-A and histone $\mathrm{H} 3$ reveals a $60 \%$ similarity within the histone fold domains with major differences concentrated in the $\mathrm{N}$ terminus (Sullivan et al. 1994). Through the following years, CENP-A homologues were identified in all eukaryotic model systems investigated: for example, HCP-3 in Caenorhabditis elegans, CID in Drosophila melanogaster, Cse4 in Saccharomyces cerevisiae, Cnp1 in Schizosaccharomyces pombe, and CenH3 in Arabidopsis thaliana (Buchwitz et al. 1999; Blower and Karpen 2001; Stoler et al. 1995; Takahashi et al. 2000; Talbert et al. 2002). Interestingly, CENP-A is poorly conserved compared to other histone proteins which are almost invariant through evolution at the amino acid level. Divergence, while extreme in the N-terminal tail of CENP-A, is prevalent even within the $\mathrm{C}$-terminal histone fold of closely related species. Even if CENP-A is poorly conserved at the sequence level, its structure or active chemical tags (i.e., acetylation and methylation) may be specific features that 
are keys to epigenetic mechanisms controlling chromosome segregation.

Understanding differences between CENP-A and histone $\mathrm{H} 3$ has long been thought to hold the answer to epigenetic regulation of centromeres. In an attempt to understand the differences in molecular dynamics between the two histone proteins, the Cleveland lab identified a specific domain of CENP-A which they called the CENP-A targeting domain (CATD) using a hydrogen/deuterium exchange technique coupled to mass spectrometry (H/DX-MS). With this technique, they showed less deuterium exchange in the CATD domain of CENP-A and thus concluded that the CATD is less flexible and more compacted (Black et al. 2004; Black et al. 2007a). Remarkably, the CATD domain was shown to be sufficient for CENP-A localization to centromeres as demonstrated by swapping the CATD domain from CENPA in histone $\mathrm{H} 3$ chimeric proteins (Black et al. 2007b). This exciting result was later shown to be due to recognition by a centromere-specific chaperone protein, Holiday junctionrecognizing protein (HJURP, see below) (Bassett et al. 2012). Consistent with protein structure playing a critical role, HJURP binding to CENP-A-H4 induces more compaction and less flexibility compared to a control condition. Thus, it is clear that structural distinction in CENP-A is essential for centromere identity and function.

Subsequent structural studies have yielded a more precise understanding of the atomic differences between $\mathrm{H} 3$ and CENP-A nucleosomes. For instance, the CENP-A-H4 tetramer crystal obtained by the Black lab showed unique biophysical properties of CENP-A nucleosomes (Sekulic et al. 2010). Overlay of H3-H4 and CENP-A-H4 tetramers revealed that the centromere-specific tetramer is rotated between dimer pairs compared to $\mathrm{H} 3-\mathrm{H} 4$ tetramer. This rotation is caused by two specific residues, His104 and Leu122, located at the CENP-A/CENP-A interface. Also, these residues were shown to be essential for CENP-A localization to the centromeres. Moreover, this rotation makes the CENP-A-H4 tetramer more compacted and less flexible as demonstrated by H/DX-MS. Overall, these features make the CENP-A-H4 tetramer narrower and shorter in 2D and wider in 3D compared to $\mathrm{H} 3-\mathrm{H} 4$ tetramers. In addition, the same group demonstrated a bulged structure in the L1 loop conferred by the Arg80 and Gly81 residues. Concomitantly, Kurumizaka's group also indentified these residues and showed their importance in the stability of CENP-A localization (Tachiwana et al. 2012). This group solved the CENP-A nucleosome crystal structure and discovered that the CENP-A $\alpha \mathrm{N}$ is shorter than that of histone $\mathrm{H} 3$, although they did not demonstrate the importance of this structural feature. All together, these results clearly demonstrate significant structural differences between CENP-A and $\mathrm{H} 3$ derived octamers.

The octamer structure is not the only source of distinction between CENP-A and H3. Recent studies of DNA wrapping topology by H/DX-MS showed that residues causing structural deformation are found in the $\alpha \mathrm{N}$ part of CENP-A sequence adjacent to the DNA entry-exit site of the nucleosome (Panchenko et al. 2011). In canonical chromatin, this site is known to be recognized by diverse functional proteins, e.g., for transcriptional control by stabilization of nucleosomes, inhibition of nucleosome sliding, and compaction of chromatin in mitosis (Zlatanova et al. 2008). Even more radical differences in DNA wrapping have been reported. Henikoff's group provided evidence suggesting that centromeric DNA, instead of having a left-handed wrapping around nucleosomes with negative supercoiling, as for canonical $\mathrm{H} 3$ nucleosomes, is in fact wrapped in a right-handed manner causing positive supercoils or less negative supercoils (Furuyama and Henikoff 2009). This was shown biochemically using an extrachromosomal plasmid and determining the state of DNA by inducing structural deformation by chloroquine-infused gel electrophoresis. In summary, on one hand, we now have a good understanding of the structural differences between CENP-A and H3 nucleosomes, while on the other hand, new questions are arising regarding the precise topology of centromeric chromatin. Some progress has been made in the last year to understand if the observed structures are species and/or cell cycle specific (Bui et al. 2012; Shivaraju et al. 2012). Nonetheless, it is still controversial whether those structures are critical for CENP-A loading, incorporation, and stabilization at centromeres.

\section{Does DNA sequence have any role in centromere propagation and identity?}

For decades, centromere identity has been thought to rely on an epigenetic mechanism due to a myriad of experimental evidences, with the exception of $S$. cerevisiae. Centromere sequences are highly divergent throughout species (Fig. 1). In $S$. cerevisiae, centromeres are $125 \mathrm{bp}$ and composed of three centromere DNA elements (CDEI-III). A single mutation in the CDEII element abrogates Cse4 incorporation and leads to a loss of centromere function and cell death (Cottarel et al. 1989; Spencer and Hieter 1992). In S. pombe, centromeres consist of 40 to $100 \mathrm{kbp}$ of repeated and inverted sequences (Clarke et al. 1986; Fishel et al. 1988). D. melanogaster centromeres are repeats of transposon and satellite sequences (AATAT and CTCTT) that can measure up to 420 kbp (Murphy and Karpen 1995; Sun et al. 1997). In humans, centromeres are composed of $\mathrm{A} / \mathrm{T}$ rich $\alpha$-satellite repeat sequences of $171 \mathrm{bp}$ arranged in a head to tail orientation, ranging in total size from 1 up to $5 \mathrm{Mbp}$ (Tyler-Smith et al. 1993; Manuelidis 1978; Mitchell et al. 1985; Willard 1985). Interestingly, human centromeres vary in genetic length on different chromosomes. The discovery of 


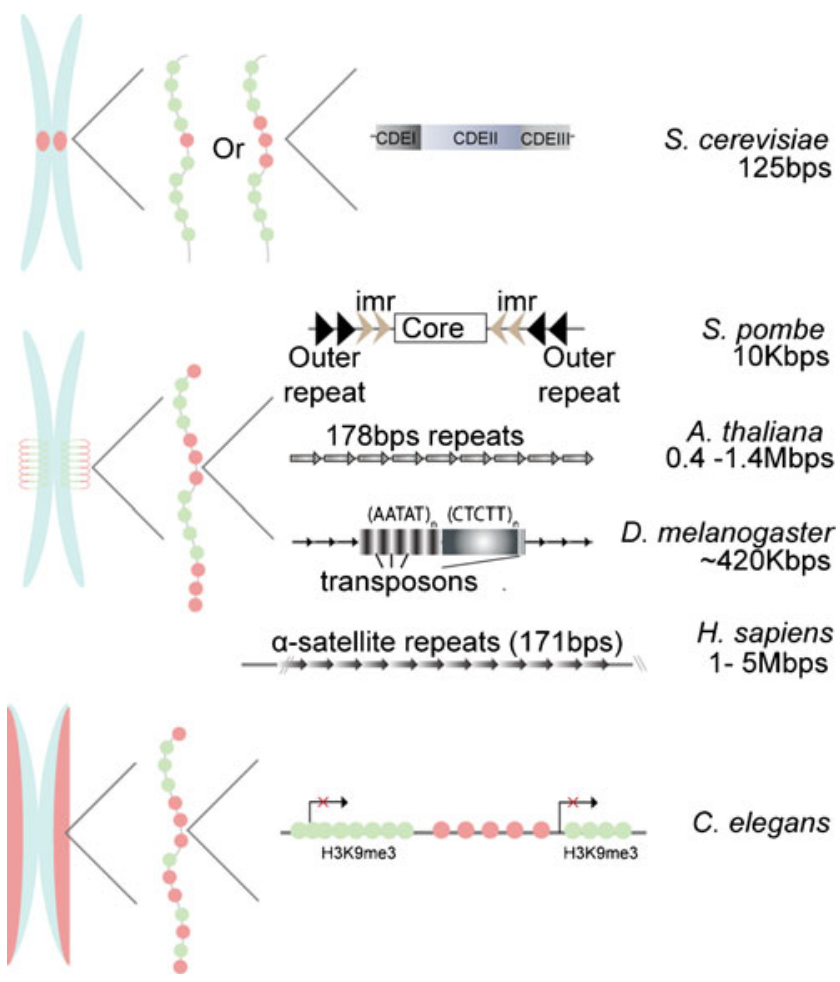

Fig. 1 Centromeric DNA sequences are not conserved through species. With the exception of $S$. cerevisiae, most evidence shows that DNA sequence has no role in centromere identity. Species comparison reveals vast differences in nucleotide composition as well as the centromere length. S. cerevisiae has a 125 -bp centromere which is divided in three centromere DNA elements (CDE), with CDEII being the sequence important for Cse4 incorporation. It is still somewhat controversial whether this centromere is composed of a single or two to three CENP-A nucleosomes.(Lawrimore et al. 2011; Furuyama and Biggins 2007) S. pombe $10 \mathrm{kbp}$ centromere consists of inner and outer repeats located outside the core region and in a head-to-head orientation. D. melanogaster has relatively large centromeres made up of DNA repeats and transposon elements for a genomic size of $\sim 420 \mathrm{kbp}$. A. thaliana and Homo sapiens centromeres are made of head-to-tail $171-178 \mathrm{bp}$ repeats that can go up to $1.4 \mathrm{Mbp}$ for the plant and $5 \mathrm{Mbp}$ for human. General centromere structures display two general types of centromere: monocentric for $S$. cerevisiae to $H$. sapiens, and holocentric (whole length of chromosome) for C. elegans (generally nematodes and several other species) (Maddox et al. 2004; Melters et al. 2012) Elongated centromeric chromatin may have different arrangements of CENP-A and $\mathrm{H} 3$ nucleosomes arrays, which are repetitive and exclusive from one another (Blower et al. 2002). When compacted, the CENP-A arrays form a hypothetical centromeric plate required for kinetochore formation in mitosis. Green circles H3 nucleosome, red circles CENP-A nucleosome

neocentromeres in humans is the key experimental evidence (provided by the stochastic nature of biology) for epigenetic regulation of centromeres. Found in exceedingly low frequency, neocentromeres form on a unique chromosomal locus distinct, and typically displaced by mega bases, from the "normal" centromere genomic position. This genomic displacement is not due to translocation or rearrangements and represents a novel epigenetic event. Neocentromeres contain CENP-A nucleosomes and are able to direct assembly of functional kinetochores supporting normal development, all in the absence of $\alpha$-satellite DNA (Warburton et al. 1997). In addition, considering that $\alpha$-satellite sequences can be found in non-centromeric loci (called inactive centromere), it is assumed that DNA sequence is not sufficient to incorporate CENP-A and build a functional kinetochore (Van Hooser et al. 2001; Earnshaw et al. 1989; Haaf et al. 1992; Warburton et al. 1997). To demonstrate this point, experiments performed by Earnshaw's group on dicentric chromosomes showed that only the active centromere, and not an inactive one, can build a functional kinetochore (by recruiting CENP-C and nucleating kinetochore assembly) even if the two centromeres are composed of $\alpha$-satellite DNA (Fig. 2). In sum, all observations lead to the conclusion that centromeric DNA is neither necessary nor sufficient for centromere identity (with the noteworthy exception of $S$. cerevisiae).

There is a clear distinction to make between centromere propagation and de novo formation. Recently, evidence has emerged to indicate a role for centromeric DNA sequences in de novo formation of centromeres. Human alphoid DNA repeats found at centromeres can be classified into two types: $\alpha 21-\mathrm{I}$ and $\alpha 21-\mathrm{II}$, with $\alpha 21-\mathrm{I}$ containing a $17-\mathrm{bp}$ sequence called the CENP-B box (Ikeno et al. 1994). The

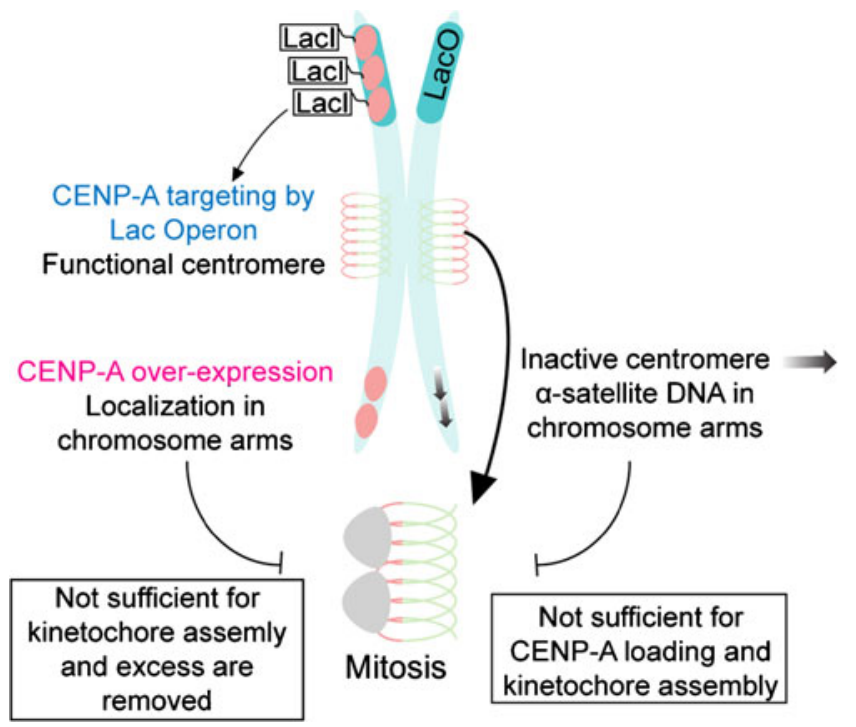

Fig. 2 Compacted CENP-A chromatin promotes kinetochore assembly and centromere propagation. An inactive centromere, which is a chromosomal locus having alpha-satellite sequence without CENP-A protein, demonstrated that centromeric sequence is not sufficient for kinetochore assembly. Kinetochore proteins are recruited to this chromosomal locus only when CENP-A is present (active centromere) (Warburton et al. 1997). Conversely, when CENP-A is overexpressed in cells, it incorporates on chromosome arms. However, this mislocalized CENP-A does not recruit kinetochore proteins in mitosis. Ultimately, by targeting CENP-A on chromosome arms using the lac operon technique, this creates a high-density array of CENP-A protein and forms a neocentromere: it recruits kinetochore components and is able to propagate for a limited time. Those observations suggest that CENP-A density is important for centromere identity and its essential role of kinetochore assembly 
CENP-B box is recognized and bound specifically by CENP-B, the only centromeric protein recognizing the centromeric DNA (Masumoto et al. 1989; Muro et al. 1992). Masumoto's group demonstrated that the CENP-B box together with alphoid DNA sequence is sufficient for de novo centromere formation in human tissue culture cells. These artificial centromeres contain CENP-A and are competent to recruit kinetochore components such as CENP-C and CENP-E (Ohzeki et al. 2002). C. elegans sperm DNA is known to be deficient of CENP-A protein before fertilization and gains it after entering the oocyte. Despite the lack of CENP-B protein in worms, the sperm DNA is able to form a new centromere via an unknown molecular mechanism (Gassmann et al. 2012). Another study showed that the Aurora $\mathrm{B}$ mitotic kinase, an inner centromere protein known to be required for correcting abnormal kinetochore-microtubule attachments, decreases at neocentromeres, concluding that this chromosomal environment, for an unknown reason, is less favorable for inner centromere maturation (Bassett et al. 2010). Hypothetically, decreased inner centromere assembly could be due to the DNA sequence itself, or it could also be that alphoid DNA sequences which are $\mathrm{A} / \mathrm{T}$ rich could promote a more compacted chromatin structure that is favorable for inner centromere assembly (Ganter et al. 1999; Dlakic and Harrington 1996). In summary, the precise role of centromeric DNA is still unclear; however, the fact that there is centromeric DNA signatures indicates that these genomic regions are important for centromere function.

\section{A role for CENP-A nucleosome composition in centromere propagation}

CENP-A nucleosome composition has become a fascinating debate. Some pieces of evidence demonstrate that CENP-A is an octamer while another scenario proposes it is half an octamer, a hemisome, or a tetrasome (Camahort et al. 2009; Palmer et al. 1987; Sekulic et al. 2010; Dalal et al. 2007; Williams et al. 2009; Mizuguchi et al. 2007) and reviewed in (Black and Cleveland 2011; Henikoff and Furuyama 2012). Here, we specifically describe how CENP-A nucleosome composition could be dynamic through the cell cycle and how this feature can manifest in conserved centromere identity over repetitive cell divisions.

In 2007, two key papers showed that CENP-A incorporation occurs after mitotic exit and takes place from late anaphase to early G1 (Schuh et al. 2007; Jansen et al. 2007). Using live cell imaging coupled to quantitative superresolution analysis, we showed that CENP-A loading in human cells takes the entire length of G1 (about $8 \mathrm{~h}$ ) (Lagana et al. 2009). Interestingly, in plants, CENP-A seems to be loaded in G2 as shown in two examples: $A$. thaliana and Hordeum vulgare (Lermontova et al. 2007; Lermontova et al. 2011). Regardless of the precise timing of CENP-A incorporation, it universally occurs outside of S-phase leading to a centromere identity problem in the next cell cycle. After the passage of the replication fork, canonical nucleosomes are randomly distributed onto replicated daughter strands, leaving gaps that are filled with newly synthesized histone proteins (H3, H4, H2A, and $\mathrm{H} 2 \mathrm{~B}$ ) (Smith and Stillman 1991). CENP-A nucleosomes should also be randomly distributed, but gaps will be left after the replication fork passage since newly synthesized CENP-A is not loaded in S-phase, thus diluting the epigenetic mark. Karpen's group tackled this problem and discovered that histone H3.3, another non-replication coupled histone H3 variant, fills in the gaps until the next G1 phase where it is specifically replaced by CENP-A (Dunleavy et al. 2011). Thus, centromeric chromatin is thought to be stabilized and reinforced by a combination of $\mathrm{H} 3$ variants in S-phase. An alternate model proposed by Henikoff's group relies on evidence of CENP-A hemisomes (tetramers of CENP-A/ $\mathrm{H} 4 / \mathrm{H} 2 \mathrm{~A} / \mathrm{H} 2 \mathrm{~B}$ ) at centromeres, supported by atomic force microscopy (AFM) analysis showing centromeric nucleosomes having half the height of a canonical octameric nucleosome (Dalal et al. 2007). The model suggests that CENP-A nucleosomes are split in half on each daughter strands in Sphase, keeping the centromeric epigenetic mark and the size of the centromere locus for each cell division. This is an attractive model for centromere identity preservation, which does not include an intermediate centromeric composition. However, a hemisome model does not take into account the packing of DNA as hemisomes will wrap approximately half the length of DNA compared to octamers.

Even if the hemisome model is controversial, it raises the possibility that CENP-A nucleosome composition is dynamic through the cell cycle. Recently, two papers concluded that CENP-A chromatin dynamically switches between octamer and tetramer (CENP-A-H4-H2A-H2B) compositions in different phases of the cell cycle (Bui et al. 2012; Shivaraju et al. 2012). Dalal's group measured nucleosome height and volume using AFM and they demonstrated that CENP-A nucleosomes are tetramers in G1, convert into octamers in early $\mathrm{S}$, and revert back into tetramers at the end of S-phase. Whereas the Gerton lab, using fluorescence correlation spectroscopy (FCS) coupled to calibrated imaging, observed that yeast centromeres have one copy of Cse4 during the majority of the cell cycle and two copies at anaphase B. There are caveats with these results however. AFM data are based on affinity purification of centromeric nucleosomes whose precise biochemical makeup is not clear. Thus, differences in height could be attributed to the presence of additional proteins or other artifacts generated in the purification scheme. FCS is a powerful technique that uses peak fluorescence intensity from a diffraction limited spot (less than $300 \mathrm{~nm}$ in this case) to determine protein 
concentration and diffusion rates. However, yeast centromeres are often dispersed (especially in metaphase) and do not all occupy a diffraction limited spot, which would result in an underestimation of Cse 4 number. During anaphase, yeast centromeres are highly compacted fitting nicely into a diffraction limited spot. This topographical difference would nicely explain the FCS results. Regardless, centromere identity and composition are necessarily dynamic because of genome replication. It will be of great interest to determine if these observations are born out by the test of time.

\section{CENP-A loading onto centromeric chromatin is a three-step mechanism}

It has been clearly demonstrated in virtually every model system that nucleosome components (H3, H4, H2A, and H2B) are expressed in S-phase (Prescott 1966; Borun et al. 1975). Nucleosome assembly occurs in an ordered manner with the help of chaperone proteins, such as CAF-1 and Asfl, and the resultant octamers are formed after the replication fork (Smith and Stillman 1991, 1989; Hayashi et al. 2004). However, CENP-A, like other histone variants, has a distinct expression pattern. Human CENP-A mRNA peaks in G2 prior to mitosis, and its incorporation is restricted to G1 phase as discussed above (Shelby et al. 2000; Jansen et al. 2007; Schuh et al. 2007; Hemmerich et al. 2008). CENP-A incorporation in this window of the cell cycle is very interesting and raises many questions. One model wherein mitotic forces transmitted through kinetochore microtubule attachments somehow modify centromere structure was disproven by bypassing the spindle assembly checkpoint (O'Connell et al. 2008). Centromeres that never experienced forces (due to absence of microtubules) incorporated new CENP-A with normal G1 timing (Jansen et al. 2007; Schuh et al. 2007). Thus, the cellular mechanism propagating centromere identity in G1 is still largely obscure on a cell biological level.

On the molecular level, several studies have addressed the mechanism of CENP-A loading onto centromeric chromatin. Currently, a three-step mechanism loosely describes the process: (1) recognition and licensing of centromeres, (2) loading of newly synthesized CENP-A with the help of chaperone proteins, and (3) maintenance of newly incorporated CENP-A (Fig. 3a).

1. Recognition and licensing of centromeres

Recognition of centromeric chromatin for CENP-A loading only at centromeres is a complex question. In 2007, a licensing complex, also called the Mis18 complex, consisting of KNL-2 (M18BP1, hereafter referred to as KNL-2) and its partners Mis $18 \alpha / \beta$ was shown to be required for CENP-A localization to centromeres in diverse model systems (Fujita et al. 2007; Maddox et al. 2007). Our understanding of the mechanism of the licensing complex is limited; however, it is clear that its recruitment to centromeres following anaphase is the most upstream event known for CENP-A deposition. It has been proposed that CENP-C recruits the licensing complex (Moree et al. 2011; Dambacher et al. 2012). This model is based on the observation that KNL-2 had reduced localization at centromeres when CENP-C was depleted in Xenopus egg extracts (Moree et al. 2011). However, KNL-2 localization is not fully lost and CENP-C is clearly downstream of KNL-2 in other model systems (Maddox et al. 2007; Fujita et al. 2007). Thus, the question of how the licensing factors recognize and bind centromeric chromatin with high specificity and subsequently recruit downstream components required for CENP-A loading needs more investigation.

2. Loading of newly synthesized CENP-A with the help of chaperone proteins

There have been two factors identified that stabilize the CENP-A/H4 complex, RbAp46/48 (Mis16, a member of the CAF-1 complex) and HJURP (or SCM3 in yeast). These essential proteins were shown to be required to prevent the degradation of soluble CENP-A molecules and thus considered chaperones (Foltz et al. 2009; Dunleavy et al. 2009; Hayashi et al. 2004). As $\mathrm{RbAp} 46 / 48$ seems to be a nonspecific histone chaperone, research has focused on HJURP showing it to have nucleosome assembly activity specifically for newly synthesized CENP-A (Dunleavy et al. 2009; Foltz et al. 2009; Barnhart et al. 2011). The CENP-A binding domain in the N-terminus of HJURP recognizes the CATD, localized in the histone fold domain within the L1 and $\alpha 2$, of CENP-A (Shuaib et al. 2010). Further details of the nature of this interaction were uncovered by co-structural studies of HJURP and CENP-A/H4, identifying specific residues mediating direct binding (Hu et al. 2011b). Although it is well accepted that HJURP recognizes CENP-A through CATD binding, in 2012, the Black lab discovered another binding interface located in the N-terminus of CENP-A (Bassett et al. 2012). This distinct interface is not required for the specificity of the binding but rather for stabilization, a mechanism that results in changing the structure of the histone fold domains of both CENP-A and H4. H3 nucleosome assembly order is well described in the literature; a histone $\mathrm{H} 3 / \mathrm{H} 4$ tetramer first sits on the DNA and then two H2A/H2B dimers complete the assembly (Smith and Stillman 1991). However, some biochemical and structural studies show that HJURP binds a dimer of CENP-A/H4 (Hu et al. 2011a). Thus, it is unclear which CENP-A/H4 complex (dimer or tetramer) gets incorporated in the centromeric chromatin. Regardless of the stoichiometry, HJURP localization to centromeres in G1 is dependent on the licensing complex; however, 


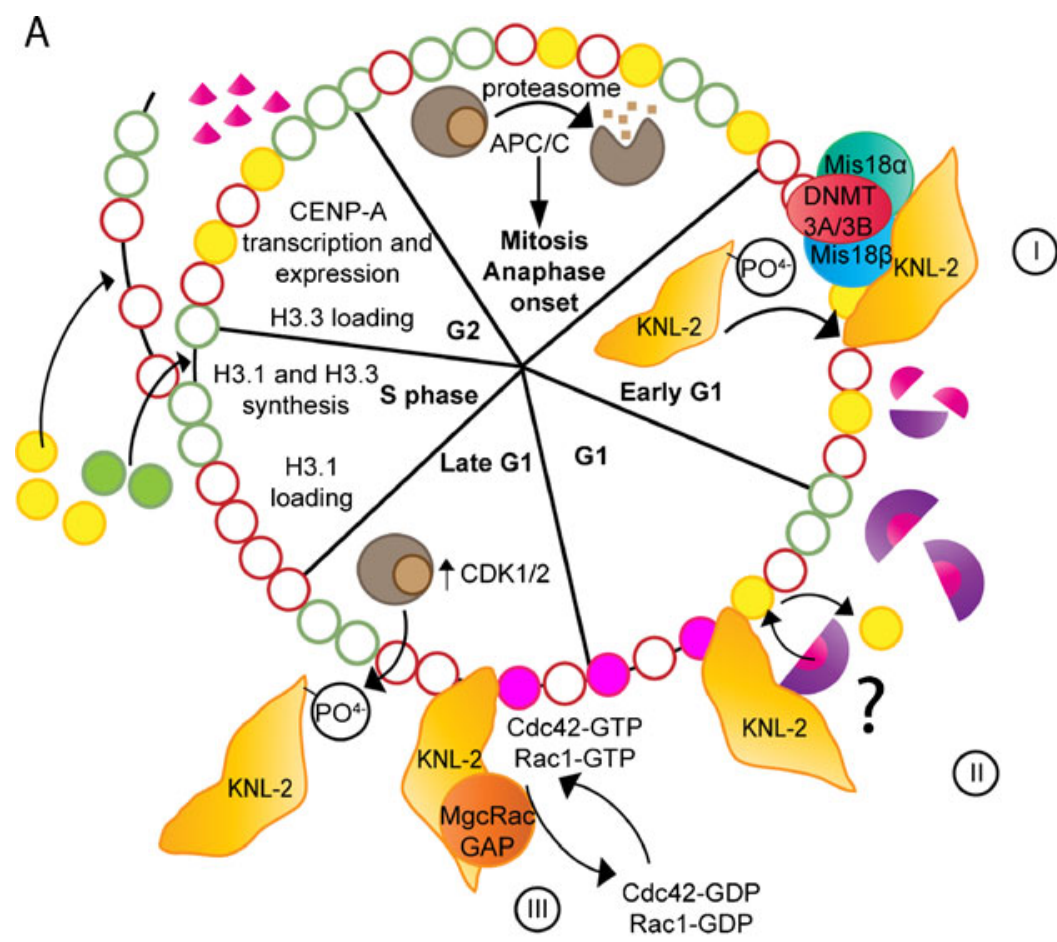

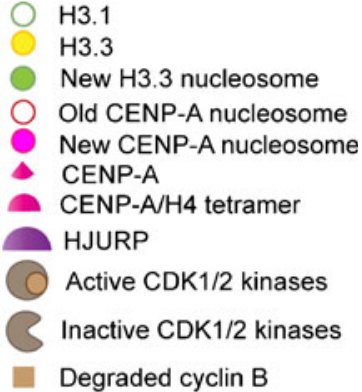

(I) Licensing
(II) Loading
(III) Maintenance

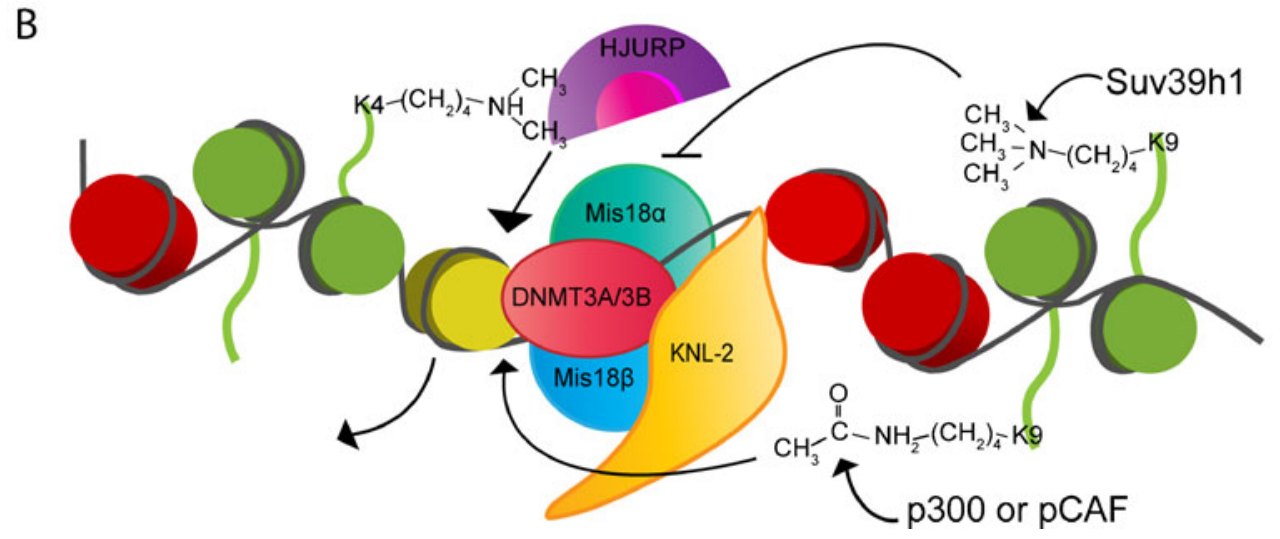

Fig. 3 CENP-A incorporation is cell cycle regulated and depends on epigenetic marks. a CENP-A incorporation is a replicationindependent mechanism; CENP-A-H4 tetramers are loaded in G1 instead of S-phase as for $\mathrm{H} 3-\mathrm{H} 4$ tetramers. The incorporation is a three-step mechanism: I-Licensing, II-Loading, and III-Maintenance. First, the licensing complex (KNL-2, Mis $18 \alpha$ and $\beta$ ) recognizes and binds the centromeric chromatin. This will license the centromere for loading of newly synthesized CENP-A. Next, the licensing complex recruits, by an unknown mechanism, the CENP-A chaperone HJURP which directly binds and stabilizes CENP-A/H4 complexes. Finally, when newly synthesized CENP-A is incorporated, a mark is removed or CENP-A conformation is changed in order to change the newly synthesized identity to that of an old one. Cdc42 or Rac1 might be part of this cellular process through the action of the GAP MgcRacGAP and the GEF ECT-2. CENP-A loading to centromeres is regulated through the cell cycle by the CDK1/2 kinases, which phosphorylate
KNL-2 in mitosis and block its localization to centromeres. At anaphase onset, CDK activity diminishes, KNL-2 is dephosphorylated and is able to localize to centromeres. b CENP-A incorporation to centromeres also depends on a post-translational modification of histone $\mathrm{H} 3$. H3K4 dimethylation is important to eventually HJURP, which localizes to centromeres and loads newly synthesized CENP-A. H3K9 trimethylation by the methyltransferase Suv39h1 inhibits CENP-A loading to centromeres, whereas $\mathrm{H} 3 \mathrm{~K} 9$ acetylation by the histone acetyl transferase (HAT) p300 or pCAF triggers CENP-A loading at centromeres. We hypothesize that KNL-2 to binds the linker DNA in the centromeric chromatin and, together with its partners Mis $18 \alpha$ and Mis $18 \beta$, this protein complex acts as a licensing mark of centromeres for CENP-A loading. Also, a DNA methyltransferase DNMT3A and DNMT3B interacts with Mis $18 \alpha$, and depletion of the protein leads to a decrease of other epigenetic marks such as $\mathrm{H} 3 \mathrm{~K} 9 \mathrm{me} 2, \mathrm{H} 3 \mathrm{~K} 9 \mathrm{~m} 3$, and $\mathrm{H} 3 \mathrm{~K} 4 \mathrm{me} 2$ at centromeric loci 
direct binding of the licensing complex components and HJURP has not been observed (Barnhart et al. 2011; Lagana et al. 2009; Fujita et al. 2007).

3. Maintenance of newly incorporated CENP-A

Immunoprecipitation of KNL-2 allowed our group to identify a new protein involved in centromere identity, MgcRacGAP (Lagana et al. 2009). This GTPase activating protein was previously described as part of the centralspindlin complex with a role in cytokinesis via regulation of Rho-type small G-proteins (Mishima et al. 2002; Canman et al. 2008). Nevertheless, two independent labs had revealed a possible role for MgcRacGAP in centromere function (Izuta et al. 2006; Perpelescu et al. 2009). In our study, we showed that MgcRacGAP localizes to centromeres in late $\mathrm{G} 1$ for a brief ( 1 to $2 \mathrm{~h}$ ) window following CENP-A loading. Depletion of MgcRacGAP resulted in the loss of newly incorporated CENP-A nucleosomes. Interestingly, a GAP dead mutant expressed in HeLa cells showed persistent localization to centromeres, and depletion of ECT-2 (the partner GTP exchange factor protein) recapitulated MgcRacGAP depletion. Thus a small GTPase cycle is likely required for maintaining CENP-A at centromeres. By depleting known small GTPases, we identified $\mathrm{Cdc} 42$ and Rac1 as possible targets of MgcRacGAP and ECT-2, and localization studies led us to favor Cdc42 as the relevant small GTPase. Since the localization of MgcRacGAP to centromeres is very late in G1 and depletion resulted in loss of centromere stability, we hypothesized that MgcRacGAP maintains the newly incorporated CENP-A and prevents overincorporation of CENP-A. This maintenance mechanism undoubtedly requires downstream effectors that are as yet unidentified.

\section{Post-translational modifications of newly synthesized CENP-A}

The importance of histone post-translational modifications has become clear in genome regulation (Fig. 3b). Some modifications affect gene expression through activation or repression of transcription by changing chromatin compaction and state. In centromeres, histone $\mathrm{H} 3$ lysine 4 dimethylation (H3K4me2), a marker of transcriptional activation, was shown to be interspersed with CENP-A nucleosomes on elongated Drosophila and human chromatin (Sullivan and Karpen 2004). This post-translational modification was shown to be important for centromere regulation, as increased activity of the demethylase LSD1 at human artificial chromosome (HAC) centromere decreases HJURP localization (Bergmann et al. 2011). Furthermore, loss of H3K4me2 prevents loading of newly synthesized CENP-A to this alphoid DNA, revealing an important role of this posttranslational modification for CENP-A localization to centromere. In the same study, a loss of $\mathrm{H} 3 \mathrm{~K} 4 \mathrm{me} 2$ decreased the transcription of alphoid DNA; however, this was not clearly demonstrated to have a direct role with HJURP localization and CENP-A loading. As post-translational modifications such as $\mathrm{H} 3 \mathrm{~K} 4 \mathrm{me} 2$ affect chromatin compaction state, the physical topology of centromeric chromatin is likely to be critical for CENP-A localization. Additionally, Masumoto's group demonstrated that histone H3 lysine 9 trimethylation (H3K9me3) prevents de novo CENP-A assembly on HAC alphoid DNA by tethering Suv39h1 (a methyltransferase) at this specific locus in mammalian cells (Ohzeki et al. 2012). Also, after depleting Suv39h1, an increase in CENP-A at HAC alphoid DNA was observed. On the other hand, tethering of histone acetyltransferases $\mathrm{p} 300$ or pCAF increased the acetylation state of $\mathrm{H} 3 \mathrm{~K} 9$ and also increased CENP-A level at alphoid DNA. This modification is important only for de novo CENP-A assembly, as removal of acetyltransferases from cells did not affect preexisting centromeres over several cell divisions.

Interestingly, the balance between methylation and acetylation of $\mathrm{H} 3 \mathrm{~K} 9$ is linked generally to transcriptional activity indicating a possible link between with CENP-A localization to centromeres. In support of this hypothesis, the Desai lab demonstrated by genomic studies in C. elegans that CENP-A is incorporated in regions of low germline transcriptional activity (Fig. 1) (Gassmann et al. 2012). One possible mechanism linking post-translational modification, transcription, and CENP-A localization to centromeres could be explained by the observations that RNA polymerase II together with its associated transcription factors are localized to centromeres and these active proteins increase $\alpha$-satellite transcripts (Chan et al. 2011). Interestingly, inhibition of RNA polymerase II decreased CENP-C localization to centromeres; however, it is unclear if this is cause or effect.

DNA, as well as histone proteins, can be modified by methylation on cytosines of $\mathrm{CpG}$ islands. This state of the chromatin is usually linked to transcription repression due to chromatin compaction (Gros et al. 2012). Interestingly, a DNA methyltransferase enzyme called DNMT3A/3B has been shown to co-localize with Mis $18 \alpha$ in mouse embryonic fibroblast cells (Kim et al. 2012). Depletion of Mis $18 \alpha$ protein leads to a decrease in centromere DNA methylation as well as a decrease of DNMT3A localization to centromeres. Moreover, this depletion leads to a decrease of some post-translational marks on histone H3 such as $\mathrm{H} 3 \mathrm{~K} 9 \mathrm{me} 2, \mathrm{H} 3 \mathrm{~K} 9 \mathrm{~m} 3$, and $\mathrm{H} 3 \mathrm{~K} 4 \mathrm{me} 2$ at centromeric locus of chromosomes. However, this study does not demonstrate a direct link between those modifications, transcription of $\alpha$-satellite DNA, and CENP-A localization to centromeres. All together, there is clear evidence that 
post-translational modifications of centromeric chromatin affect CENP-A loading. This field of research is blooming and we expect great advances in the near future providing a better understanding of those modifications in centromere identity.

\section{CENP-A loading to centromere is regulated by cell cycle kinase}

The timing of CENP-A loading invokes clear hypotheses of a cell cycle-dependent mechanism. Recently, the Jansen lab nicely demonstrated that cyclin-dependent kinases (CDKs) temporally regulate CENP-A loading to centromeres (Silva et al. 2012). Synchronized human cells treated with roscovitine, a CDK1 and 2 inhibitor, showed apparently normal, however mis-timed, CENP-A assembly in G2. More precisely, they demonstrated a role for CDK1 as the kinase regulating CENP-A loading. Using DT40 avian cell line, which is genetically null for CDK2, and inhibiting CDK1 function chemically, the authors observed an inappropriate CENP-A loading in G2, compared to control DT40 cells. Also, this regulation seems to be at the level of KNL-2, as expression of a mutant form with 24 potential phosphorylation sites changed to alanine also resulted in precocious localization of KNL-2 and downstream CENP-A loading in otherwise untreated G2 cells. This regulation through CDK activity is only true for KNL-2 and did not have any influences on the other licensing complex components. Thus, CENP-A loading is inversely timed relative to mitotic CDK activity and KNL-2 seems to be the most upstream component of the centromere epigenetic regulation pathway (Fig. 3a). It is not clear if these rules will hold true for plants where CENP-A loading is in G2; however, some cell cycle timing mechanism must exist in these models also.

\section{Is the ultimate mark for centromere identity CENP-A?}

The epigenetic mechanism for centromere identity has been well defined over the years. However, only recently was it shown that CENP-A is sufficient to drive centromeric identity over multiple cell divisions (Fig. 4). This was accomplished by generating a high-density region of CENP-A chromatin; it is needed because previous overexpression experiments resulted in CENP-A incorporation in the chromosome arms, however no kinetochore assembly. Briefly, many repeats of the lac operon were integrated in series at a non-centromeric (region on a chromosome arm) locus in flies (Mendiburo et al. 2011). Overexpression of LacI fused to CID (CENP-A) resulted in CID incorporation ectopically, and this ectopic centromere recruited kinetochore components. Remarkably, these ectopic centromeres can, with extremely low fidelity, functionally replace the endogenous centromeres for a short period of time. Similar studies fusing HJURP to LacI in human cells also generated localized high-density arrays of CENP-A with similar results. Interestingly, the lac operon system bypassed the need of the licensing complex for HJURP, since this technique forces direct interactions of the protein with a specific DNA sequence (Barnhart et al. 2011) (Fig. 2). This is a strong argument in favor of the licensing complex being upstream of HJURP for CENP-A loading to centromeres given that HJURP, in the absence of KNL-2 and Mis18, does not localize to normal centromeres. Therefore, high-density CENP-A chromatin is not only necessary but is sufficient for centromere identity and function.

In normal cells, the licensing complex is the first known step in recognizing centromeric. Interestingly, in C. elegans, it has been observed for quite some time that exogenous DNA injected into oocytes forms stably transmitted arrays that are properly segregated over many generations. Accordingly, the Desai lab reasoned that if this DNA is segregated, then it should form a functional kinetochore (Yuen et al. 2011). To test this hypothesis, they showed that arrays segregate passively until early embryogenesis where at the five to eight cell stages, lacO extrachromosomal arrays recruit centromeric proteins such as CENP-A, kinetochore proteins BUB1 and NDC-80, and the licensing factor KNL-2, actively segregating the array. This interesting approach demonstrated that random DNA sequences are competent for de novo centromere formation; however, the timing and the sequence of events are not defined. It should be noted that this could be specific to $C$. elegans given the fact that alphoid DNA has been demonstrated to be critical for de novo centromere formation in human cells (Ohzeki et al. 2002).

Emerging evidence is expanding our knowledge on the epigenetic mechanism of centromere identity but still raises the question: what is the first mark for centromere identity? We propose two broad possibilities: (1) CENP-A structure and the surrounding posttranslational modifications confers to centromere a specific docking site for the licensing complex to bind, loading newly synthesized CENP-A via the chaperone HJURP, (2) centromeric DNA, composed of motifs like the CENP-B box is directly recognized by the licensing complex, or centromeric DNA composition in nucleic acids confers a centromere-specific chromatin state. In either case, we propose that licensing protein KNL-2 through its $\mathrm{Myb}$ domain binds the centromeric DNA and recruits the loading of new CENP-A during G1 in human cells (Fig. 4). 


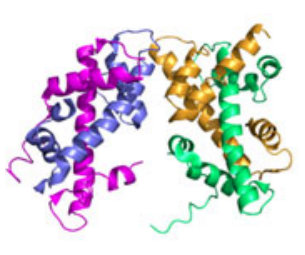

CENP-A

nucleosome structure

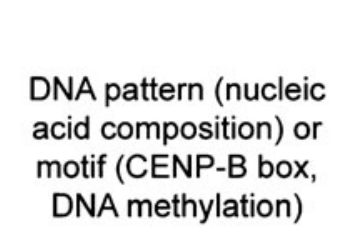

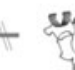

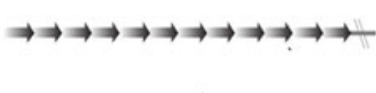

?

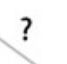

$?$

binding to

centromere

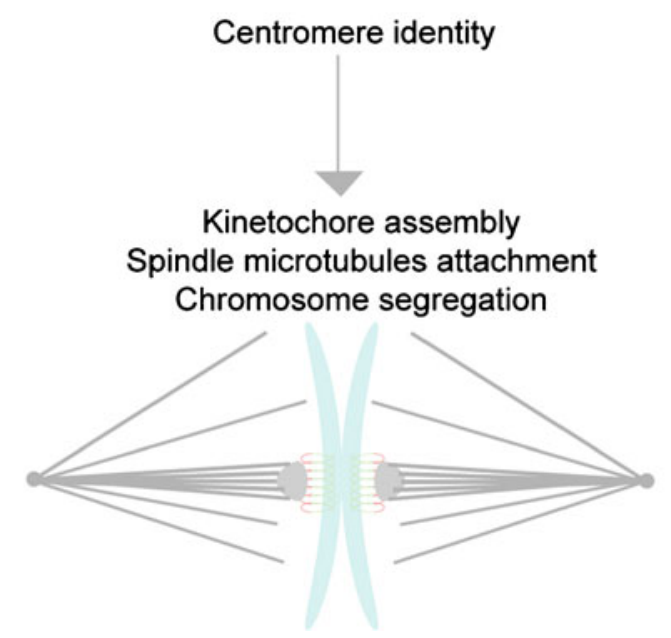

Fig. 4 What is the first epigenetic mark of centromeres? Information provided by the literature brings the question of what is the first epigenetic mark of centromeres. Some evidence has shown that CENP-A nucleosome structure might be the feature for centromere identity. However, CENP-A incorporation and localization to centromeres are not passive cellular processes; therefore, CENP-A might not be the first epigenetic mark. Centromere identity could be through genetic features of DNA sequence (nucleic acid composition) or motif (CENP-B box, DNA methylation), but strong experimental evidence

\section{The role of CENP-A in mitosis and its relation with cancer therapy}

Many labs working in a myriad of model systems have concluded that centromere identity propagation and maintenance through CENP-A is essential for cell division. CENP-A localization to centromeres creates a platform that is essential for kinetochore assembly; a loss in centromere identity results in chromosome segregation defects caused by a misattachment of chromosomes to the mitotic spindle. To date, centromere proteins such as CENP-A and KNL-2 have no known role outside of mitosis, thus making them appealing targets for chemotherapeutic development. Inhibiting centromere function leads to chromosome segregation defects and ultimately to cell death, thus possibly a potent mechanism for slowing down cancer progression. Importantly, inhibiting mitosis-specific mechanisms will diminish the possibility disputes this model. One marker that could link the two other hypotheses is KNL-2. This protein was shown to be essential for CENP-A localization to centromeres and genetically, it is the most upstream protein for this important cellular process. Thus, KNL-2 could be the first epigenetic mark of centromeres. For KNL-2 predicted structure: Orange is the SANTA domain and in purple is the Myb domain. (Published CENP-A nucleosome structure, Protein Data Bank reference \# 3AN2 (Tachiwana et al. 2012); KNL-2 predicted structure (Zhang 2008))

of undesirable side effects as seen in taxol treatment. This broadly used chemotherapeutic treatment stabilizes microtubules leading to mitotic defects and cell death. However, microtubules also have essential roles as cytoskeleton components for most cell types, including neurons. Therefore, taxol also affects microtubules in the nervous system resulting in severe undesired side effects usually accompanied by neurodegenerative pathology. Thus, investigations with the aim of elucidating how the cell manages to preserve its centromeres well defined during cell division will likely provide us with new drug targets with higher specificity for mitotic cells.

Centromere fields of research are expanding, trying to better understand the complex cellular process of centromere identity and maintenance. In the next years, our efforts will bring more highlights to the spatial and temporal regulation of CENP-A loading to centromere, thus better define the first marks of centromere identity. 
Acknowledgments We would like to thank our lab members, especially Joël Ryan for his invaluable help, Dr. Amy S. Maddox and her lab members for discussions and innovative ideas. Also, we are grateful to the centromere/kinetochore community at large for sharing ideas and exciting results. P.S.M. is the Canada Research Chair in Cell Division and Chromosomal Organization and supported by research grants from the Canadian Institutes of Health Research (MOP-106548) and Canadian Cancer Society Research Institute (700824).

Open Access This article is distributed under the terms of the Creative Commons Attribution License which permits any use, distribution, and reproduction in any medium, provided the original author(s) and the source are credited.

\section{References}

Barnhart MC, Kuich PH, Stellfox ME, Ward JA, Bassett EA, Black BE, Foltz DR (2011) HJURP is a CENP-A chromatin assembly factor sufficient to form a functional de novo kinetochore. J Cell Biol 194(2):229-243. doi:10.1083/jcb.201012017

Bassett EA, DeNizio J, Barnhart-Dailey MC, Panchenko T, Sekulic N, Rogers DJ, Foltz DR, Black BE (2012) HJURP uses distinct CENP-A surfaces to recognize and to stabilize CENP-A/histone H4 for centromere assembly. Dev Cell 22(4):749-762. doi:10.1016/j.devcel.2012.02.001

Bassett EA, Wood S, Salimian KJ, Ajith S, Foltz DR, Black BE (2010) Epigenetic centromere specification directs aurora B accumulation but is insufficient to efficiently correct mitotic errors. J Cell Biol 190(2):177-185. doi:10.1083/jcb.201001035

Bergmann JH, Rodriguez MG, Martins NM, Kimura H, Kelly DA, Masumoto H, Larionov V, Jansen LE, Earnshaw WC (2011) Epigenetic engineering shows $\mathrm{H} 3 \mathrm{~K} 4 \mathrm{me} 2$ is required for HJURP targeting and CENP-A assembly on a synthetic human kinetochore. EMBO J 30(2):328-340. doi:10.1038/emboj.2010.329

Black BE, Brock MA, Bedard S, Woods VL Jr, Cleveland DW (2007a) An epigenetic mark generated by the incorporation of CENP-A into centromeric nucleosomes. Proc Natl Acad Sci U S A 104 (12):5008-5013. doi:10.1073/pnas.0700390104

Black BE, Cleveland DW (2011) Epigenetic centromere propagation and the nature of CENP-A nucleosomes. Cell 144(4):471-479. doi:10.1016/j.cell.2011.02.002

Black BE, Foltz DR, Chakravarthy S, Luger K, Woods VL Jr, Cleveland DW (2004) Structural determinants for generating centromeric chromatin. Nature 430(6999):578-582. doi:10.1038/ nature 02766

Black BE, Jansen LE, Maddox PS, Foltz DR, Desai AB, Shah JV, Cleveland DW (2007b) Centromere identity maintained by nucleosomes assembled with histone $\mathrm{H} 3$ containing the CENP-A targeting domain. Mol Cell 25(2):309-322. doi:10.1016/ j.molcel.2006.12.018

Blower MD, Karpen GH (2001) The role of Drosophila CID in kinetochore formation, cell-cycle progression and heterochromatin interactions. Nat Cell Biol 3(8):730-739. doi:10.1038/ 35087045

Blower MD, Sullivan BA, Karpen GH (2002) Conserved organization of centromeric chromatin in flies and humans. Dev Cell 2(3):319-330

Borun TW, Gabrielli F, Ajiro K, Zweidler A, Baglioni C (1975) Further evidence of transcriptional and translational control of histone messenger RNA during the HeLa S3 cycle. Cell 4(1):59-67. doi:0092-8674(75)90134-8

Brinkley BR, Stubblefield E (1966) The fine structure of the kinetochore of a mammalian cell in vitro. Chromosoma 19(1):28-43
Buchwitz BJ, Ahmad K, Moore LL, Roth MB, Henikoff S (1999) A histone-H3-like protein in C. elegans. Nature 401(6753):547548. doi: $10.1038 / 44062$

Bui M, Dimitriadis EK, Hoischen C, An E, Quenet D, Giebe S, NitaLazar A, Diekmann S, Dalal Y (2012) Cell-cycle-dependent structural transitions in the human CENP-A nucleosome in vivo. Cell 150(2):317-326. doi:10.1016/j.cell.2012.05.035

Camahort R, Shivaraju M, Mattingly M, Li B, Nakanishi S, Zhu D, Shilatifard A, Workman JL, Gerton JL (2009) Cse4 is part of an octameric nucleosome in budding yeast. Mol Cell 35(6):794-805. doi:10.1016/j.molcel.2009.07.022

Canman JC, Lewellyn L, Laband K, Smerdon SJ, Desai A, Bowerman B, Oegema K (2008) Inhibition of Rac by the GAP activity of centralspindlin is essential for cytokinesis. Science 322 (5907):1543-1546. doi:10.1126/science.1163086

Chan FL, Marshall OJ, Saffery R, Kim BW, Earle E, Choo KH, Wong LH (2011) Active transcription and essential role of RNA polymerase II at the centromere during mitosis. Proc Natl Acad Sci U S A 109(6):1979-1984. doi:10.1073/pnas.1108705109

Clarke L, Amstutz H, Fishel B, Carbon J (1986) Analysis of centromeric DNA in the fission yeast Schizosaccharomyces pombe. Proc Natl Acad Sci U S A 83(21):8253-8257

Cottarel G, Shero JH, Hieter P, Hegemann JH (1989) A 125-base-pair CEN6 DNA fragment is sufficient for complete meiotic and mitotic centromere functions in Saccharomyces cerevisiae. Mol Cell Biol 9(8):3342-3349

Dalal Y, Wang H, Lindsay S, Henikoff S (2007) Tetrameric structure of centromeric nucleosomes in interphase Drosophila cells. PLoS Biol 5(8):e218. doi:10.1371/journal.pbio.0050218

Dambacher S, Deng W, Hahn M, Sadic D, Frohlich J, Nuber A, Hoischen C, Diekmann S, Leonhardt H, Schotta G (2012) CENP-C facilitates the recruitment of M18BP1 to centromeric chromatin. Nucleus 3(1)

Dlakic M, Harrington RE (1996) The effects of sequence context on DNA curvature. Proc Natl Acad Sci U S A 93(9):3847-3852

Dunleavy EM, Almouzni G, Karpen GH (2011) H3.3 is deposited at centromeres in $\mathrm{S}$ phase as a placeholder for newly assembled CENP-A in G(1) phase. Nucleus 2(2):146-157. doi:10.4161/ nucl.2.2.15211

Dunleavy EM, Roche D, Tagami H, Lacoste N, Ray-Gallet D, Nakamura Y, Daigo Y, Nakatani Y, Almouzni-Pettinotti G (2009) HJURP is a cell-cycle-dependent maintenance and deposition factor of CENP-A at centromeres. Cell 137 (3):485-497. doi:10.1016/j.cell.2009.02.040

Earnshaw W, Bordwell B, Marino C, Rothfield N (1986) Three human chromosomal autoantigens are recognized by sera from patients with anti-centromere antibodies. J Clin Invest 77(2):426-430. doi:10.1172/JCI112320

Earnshaw WC, Ratrie H 3rd, Stetten G (1989) Visualization of centromere proteins CENP-B and CENP-C on a stable dicentric chromosome in cytological spreads. Chromosoma 98(1):1-12

Earnshaw WC, Rothfield N (1985) Identification of a family of human centromere proteins using autoimmune sera from patients with scleroderma. Chromosoma 91(3-4):313-321

Fishel B, Amstutz H, Baum M, Carbon J, Clarke L (1988) Structural organization and functional analysis of centromeric DNA in the fission yeast Schizosaccharomyces pombe. Mol Cell Biol 8 (2):754-763

Flemming W (1882) Zellsubstanz. Kern und Zeltheilung. F.C.W Vogel, Leipzig

Foltz DR, Jansen LE, Bailey AO, Yates JR 3rd, Bassett EA, Wood S, Black BE, Cleveland DW (2009) Centromere-specific assembly of CENP-a nucleosomes is mediated by HJURP. Cell 137(3):472484. doi:10.1016/j.cell.2009.02.039

Fujita Y, Hayashi T, Kiyomitsu T, Toyoda Y, Kokubu A, Obuse C, Yanagida M (2007) Priming of centromere for CENP-A 
recruitment by human hMis18alpha, hMis18beta, and M18BP1. Dev Cell 12(1):17-30. doi:10.1016/j.devcel.2006.11.002

Furuyama S, Biggins S (2007) Centromere identity is specified by a single centromeric nucleosome in budding yeast. Proc Natl Acad Sci U S A 104(37):14706-14711. doi:10.1073/pnas.0706985104

Furuyama T, Henikoff S (2009) Centromeric nucleosomes induce positive DNA supercoils. Cell 138(1):104-113. doi:10.1016/ j.cell.2009.04.049

Ganter B, Chao ST, Lipsick JS (1999) Transcriptional activation by the myb proteins requires a specific local promoter structure. FEBS Lett 460(3):401-410

Gassmann R, Rechtsteiner A, Yuen KW, Muroyama A, Egelhofer T, Gaydos L, Barron F, Maddox P, Essex A, Monen J, Ercan S, Lieb JD, Oegema K, Strome S, Desai A (2012) An inverse relationship to germline transcription defines centromeric chromatin in C. elegans. Nature 484(7395):534-537. doi:10.1038/nature10973

Gros C, Fahy J, Halby L, Dufau I, Erdmann A, Gregoire JM, Ausseil F, Vispe S, Arimondo PB (2012) DNA methylation inhibitors in cancer: recent and future approaches. Biochimie. doi:10.1016/ j.biochi.2012.07.025

Haaf T, Warburton PE, Willard HF (1992) Integration of human alphasatellite DNA into simian chromosomes: centromere protein binding and disruption of normal chromosome segregation. Cell 70 (4):681-696

Hayashi T, Fujita Y, Iwasaki O, Adachi Y, Takahashi K, Yanagida M (2004) Mis16 and Mis18 are required for CENP-A loading and histone deacetylation at centromeres. Cell 118(6):715-729. doi:10.1016/j.cell.2004.09.002

Hemmerich P, Weidtkamp-Peters S, Hoischen C, Schmiedeberg L, Erliandri I, Diekmann S (2008) Dynamics of inner kinetochore assembly and maintenance in living cells. J Cell Biol 180 (6):1101-1114. doi:10.1083/jcb.200710052

Henikoff S, Furuyama T (2012) The unconventional structure of centromeric nucleosomes. Chromosoma 121(4):341-352. doi:10.1007/s00412-012-0372-y

Hu H, Liu Y, Wang M, Fang J, Huang H, Yang N, Li Y, Wang J, Yao X, Shi Y, Li G, Xu RM (2011a) Structure of a CENP-A-histone H4 heterodimer in complex with chaperone HJURP. Genes Dev 25 (9):901-906. doi:10.1101/gad.2045111

Hu H, Liu Y, Wang M, Fang J, Huang H, Yang N, Li Y, Wang J, Yao X, Shi Y, Li G, Xu RM (2011b) Structure of a CENP-A-histone H4 heterodimer in complex with chaperone HJURP. Genes Dev. doi: $10.1101 / \mathrm{gad} .2045111$

Ikeno M, Masumoto H, Okazaki T (1994) Distribution of CENP-B boxes reflected in CREST centromere antigenic sites on longrange alpha-satellite DNA arrays of human chromosome 21 . Hum Mol Genet 3(8):1245-1257

Izuta H, Ikeno M, Suzuki N, Tomonaga T, Nozaki N, Obuse C, Kisu Y, Goshima N, Nomura F, Nomura N, Yoda K (2006) Comprehensive analysis of the ICEN (Interphase Centromere Complex) components enriched in the CENP-A chromatin of human cells. Genes Cells 11(6):673-684. doi:10.1111/j.13652443.2006.00969.x

Jansen LE, Black BE, Foltz DR, Cleveland DW (2007) Propagation of centromeric chromatin requires exit from mitosis. J Cell Biol 176 (6):795-805. doi:10.1083/jcb.200701066

Kim IS, Lee M, Park KC, Jeon Y, Park JH, Hwang EJ, Jeon TI, Ko S, Lee H, Baek SH, Kim KI (2012) Roles of Mis18alpha in epigenetic regulation of centromeric chromatin and CENP-A loading. Mol Cell 46(3):260-273. doi:10.1016/j.molcel.2012.03.021

Lagana A, Dorn JF, De Rop V, Ladouceur AM, Maddox AS, Maddox PS (2009) A small GTPase molecular switch regulates epigenetic centromere maintenance by stabilizing newly incorporated CENP-A. Nat Cell Biol 12(12):1186-1193. doi:10.1038/ncb2129
Lawrimore J, Bloom KS, Salmon ED (2011) Point centromeres contain more than a single centromere-specific Cse4 (CENP-A) nucleosome. J Cell Biol 195(4):573-582. doi:10.1083/jcb.201106036

Lermontova I, Fuchs J, Schubert V, Schubert I (2007) Loading time of the centromeric histone $\mathrm{H} 3$ variant differs between plants and animals. Chromosoma 116(6):507-510. doi:10.1007/s00412007-0122-8

Lermontova I, Rutten T, Schubert I (2011) Deposition, turnover, and release of CENH3 at Arabidopsis centromeres. Chromosoma 120 (6):633-640. doi:10.1007/s00412-011-0338-5

Maddox PS, Hyndman F, Monen J, Oegema K, Desai A (2007) Functional genomics identifies a Myb domain-containing protein family required for assembly of CENP-A chromatin. J Cell Biol 176(6):757-763. doi:10.1083/jcb.200701065

Maddox PS, Oegema K, Desai A, Cheeseman IM (2004) "Holo" er than thou: chromosome segregation and kinetochore function in C. elegans. Chromosome Res 12(6):641-653. doi:10.1023/B: CHRO.0000036588.42225.2f

Manuelidis L (1978) Chromosomal localization of complex and simple repeated human DNAs. Chromosoma 66(1):23-32

Masumoto H, Masukata H, Muro Y, Nozaki N, Okazaki T (1989) A human centromere antigen (CENP-B) interacts with a short specific sequence in alphoid DNA, a human centromeric satellite. J Cell Biol 109(5):1963-1973

Melters DP, Paliulis LV, Korf IF, Chan SW (2012) Holocentric chromosomes: convergent evolution, meiotic adaptations, and genomic analysis. Chromosome Res 20(5):579-593. doi:10.1007/ s10577-012-9292-1

Mendiburo MJ, Padeken J, Fulop S, Schepers A, Heun P (2011) Drosophila CENH3 is sufficient for centromere formation. Science 334(6056):686-690. doi:10.1126/science.1206880

Mishima M, Kaitna S, Glotzer M (2002) Central spindle assembly and cytokinesis require a kinesin-like protein/RhoGAP complex with microtubule bundling activity. Dev Cell 2(1):41-54

Mitchell AR, Gosden JR, Miller DA (1985) A cloned sequence, p82H, of the alphoid repeated DNA family found at the centromeres of all human chromosomes. Chromosoma 92(5):369-377

Mizuguchi G, Xiao H, Wisniewski J, Smith MM, Wu C (2007) Nonhistone $\mathrm{Scm} 3$ and histones $\mathrm{CenH} 3-\mathrm{H} 4$ assemble the core of centromere-specific nucleosomes. Cell 129(6):1153-1164. doi:10.1016/j.cell.2007.04.026

Moree B, Meyer CB, Fuller CJ, Straight AF (2011) CENP-C recruits M18BP1 to centromeres to promote CENP-A chromatin assembly. J Cell Biol 194(6):855-871. doi:10.1083/jcb.201106079

Muro Y, Masumoto H, Yoda K, Nozaki N, Ohashi M, Okazaki T (1992) Centromere protein B assembles human centromeric alpha-satellite DNA at the 17-bp sequence, CENP-B box. J Cell Biol 116(3):585-596

Murphy TD, Karpen GH (1995) Localization of centromere function in a Drosophila minichromosome. Cell 82(4):599-609

O'Connell CB, Loncarek J, Hergert P, Kourtidis A, Conklin DS, Khodjakov A (2008) The spindle assembly checkpoint is satisfied in the absence of interkinetochore tension during mitosis with unreplicated genomes. J Cell Biol 183(1):29-36. doi:10.1083/ jcb.200801038

Ohzeki J, Bergmann JH, Kouprina N, Noskov VN, Nakano M, Kimura H, Earnshaw WC, Larionov V, Masumoto H (2012) Breaking the HAC barrier: histone $\mathrm{H} 3 \mathrm{~K} 9$ acetyl/methyl balance regulates CENP-A assembly. EMBO J 31(10):2391-2402. doi:10.1038/ emboj. 2012.82

Ohzeki J, Nakano M, Okada T, Masumoto H (2002) CENP-B box is required for de novo centromere chromatin assembly on human alphoid DNA. J Cell Biol 159(5):765-775. doi:10.1083/ jcb.200207112

Palmer DK, O'Day K, Trong HL, Charbonneau H, Margolis RL (1991) Purification of the centromere-specific protein CENP-A and 
demonstration that it is a distinctive histone. Proc Natl Acad Sci U S A 88(9):3734-3738

Palmer DK, O'Day K, Wener MH, Andrews BS, Margolis RL (1987) A $17-\mathrm{kDa}$ centromere protein (CENP-A) copurifies with nucleosome core particles and with histones. J Cell Biol 104(4):805-815

Panchenko T, Sorensen TC, Woodcock CL, Kan ZY, Wood S, Resch MG, Luger K, Englander SW, Hansen JC, Black BE (2011) Replacement of histone $\mathrm{H} 3$ with CENP-A directs global nucleosome array condensation and loosening of nucleosome superhelical termini. Proc Natl Acad Sci U S A 108(40):16588-16593. doi:10.1073/pnas.1113621108

Perpelescu M, Nozaki N, Obuse C, Yang H, Yoda K (2009) Active establishment of centromeric CENP-A chromatin by RSF complex. J Cell Biol 185(3):397-407. doi:10.1083/jcb.200903088

Prescott DM (1966) The syntheses of total macronuclear protein, histone, and DNA during the cell cycle in Euplotes eurystomus. J Cell Biol 31(1):1-9

Robbins E, Gonatas NK (1964) The ultrastructure of a mammalian cell during the mitotic cycle. J Cell Biol 21:429-463

Schuh M, Lehner CF, Heidmann S (2007) Incorporation of Drosophila CID/CENP-A and CENP-C into centromeres during early embryonic anaphase. Curr Biol 17(3):237-243. doi:10.1016/j.cub.2006.11.051

Sekulic N, Bassett EA, Rogers DJ, Black BE (2010) The structure of (CENP-A-H4)(2) reveals physical features that mark centromeres. Nature 467(7313):347-351. doi:10.1038/nature09323

Shelby RD, Monier K, Sullivan KF (2000) Chromatin assembly at kinetochores is uncoupled from DNA replication. J Cell Biol 151 (5): $1113-1118$

Shivaraju M, Unruh JR, Slaughter BD, Mattingly M, Berman J, Gerton JL (2012) Cell-cycle-coupled structural oscillation of centromeric nucleosomes in yeast. Cell 150(2):304-316. doi:10.1016/j.cell.2012.05.034

Shuaib M, Ouararhni K, Dimitrov S, Hamiche A (2010) HJURP binds CENP-A via a highly conserved N-terminal domain and mediates its deposition at centromeres. Proc Natl Acad Sci U S A 107 (4):1349-1354. doi:10.1073/pnas.0913709107

Silva MC, Bodor DL, Stellfox ME, Martins NM, Hochegger H, Foltz DR, Jansen LE (2012) Cdk activity couples epigenetic centromere inheritance to cell cycle progression. Dev Cell 22(1):52-63. doi:10.1016/j.devcel.2011.10.014

Smith S, Stillman B (1989) Purification and characterization of CAF-I, a human cell factor required for chromatin assembly during DNA replication in vitro. Cell 58(1):15-25

Smith S, Stillman B (1991) Stepwise assembly of chromatin during DNA replication in vitro. EMBO J 10(4):971-980

Spencer F, Hieter P (1992) Centromere DNA mutations induce a mitotic delay in Saccharomyces cerevisiae. Proc Natl Acad Sci U S A 89(19):8908-8912

Stoler S, Keith KC, Curnick KE, Fitzgerald-Hayes M (1995) A mutation in CSE4, an essential gene encoding a novel chromatinassociated protein in yeast, causes chromosome nondisjunction and cell cycle arrest at mitosis. Genes Dev 9(5):573-586

Sullivan BA, Karpen GH (2004) Centromeric chromatin exhibits a histone modification pattern that is distinct from both euchromatin and heterochromatin. Nat Struct Mol Biol 11(11):1076-1083. doi: $10.1038 / \mathrm{nsmb} 845$
Sullivan KF, Hechenberger M, Masri K (1994) Human CENP-A contains a histone $\mathrm{H} 3$ related histone fold domain that is required for targeting to the centromere. J Cell Biol 127(3):581-592

Sun X, Wahlstrom J, Karpen G (1997) Molecular structure of a functional Drosophila centromere. Cell 91(7):1007-1019

Tachiwana H, Kagawa W, Shiga T, Osakabe A, Miya Y, Saito K, Hayashi-Takanaka Y, Oda T, Sato M, Park SY, Kimura H, Kurumizaka H (2012) Crystal structure of the human centromeric nucleosome containing CENP-A. Nature 476(7359):232235. doi:10.1038/nature10258

Takahashi K, Chen ES, Yanagida M (2000) Requirement of Mis6 centromere connector for localizing a CENP-A-like protein in fission yeast. Science 288(5474):2215-2219

Talbert PB, Masuelli R, Tyagi AP, Comai L, Henikoff S (2002) Centromeric localization and adaptive evolution of an Arabidopsis histone H3 variant. Plant Cell 14(5):1053-1066

Tyler-Smith C, Oakey RJ, Larin Z, Fisher RB, Crocker M, Affara NA, Ferguson-Smith MA, Muenke M, Zuffardi O, Jobling MA (1993) Localization of DNA sequences required for human centromere function through an analysis of rearranged $\mathrm{Y}$ chromosomes. Nat Genet 5(4):368-375. doi:10.1038/ng1293-368

Valdivia MM, Brinkley BR (1985) Fractionation and initial characterization of the kinetochore from mammalian metaphase chromosomes. J Cell Biol 101(3):1124-1134

Van Hooser AA, Ouspenski II, Gregson HC, Starr DA, Yen TJ, Goldberg ML, Yokomori K, Earnshaw WC, Sullivan KF, Brinkley BR (2001) Specification of kinetochore-forming chromatin by the histone H3 variant CENP-A. J Cell Sci 114(Pt 19):3529-3542

Warburton PE, Cooke CA, Bourassa S, Vafa O, Sullivan BA, Stetten G, Gimelli G, Warburton D, Tyler-Smith C, Sullivan KF, Poirier GG, Earnshaw WC (1997) Immunolocalization of CENP-A suggests a distinct nucleosome structure at the inner kinetochore plate of active centromeres. Curr Biol 7(11):901-904

Willard HF (1985) Chromosome-specific organization of human alpha satellite DNA. Am J Hum Genet 37(3):524-532

Williams JS, Hayashi T, Yanagida M, Russell P (2009) Fission yeast Scm3 mediates stable assembly of Cnp1/CENP-A into centromeric chromatin. Mol Cell 33(3):287-298. doi:10.1016/ j.molcel.2009.01.017

Yoda K, Ando S, Morishita S, Houmura K, Hashimoto K, Takeyasu K, Okazaki T (2000) Human centromere protein A (CENP-A) can replace histone $\mathrm{H} 3$ in nucleosome reconstitution in vitro. Proc Natl Acad Sci U S A 97(13):7266-7271. doi:10.1073/ pnas.130189697

Yuen KW, Nabeshima K, Oegema K, Desai A (2011) Rapid de novo centromere formation occurs independently of heterochromatin protein 1 in C. elegans embryos. Curr Biol 21(21):1800-1807. doi:10.1016/j.cub.2011.09.016

Zhang Y (2008) I-TASSER server for protein 3D structure prediction. BMC Bioinformatics 9:40. doi:10.1186/1471-2105-9-40

Zlatanova J, Seebart C, Tomschik M (2008) The linker-protein network: control of nucleosomal DNA accessibility. Trends Biochem Sci 33(6):247-253. doi:10.1016/j.tibs.2008.04.001 